\title{
LABORATORY EXPERIMENT TO INVESTIGATE PERMEABILITY CHANGE IN TIGHT SANDSTONE SAMPLES IN CASE OF WATER BASED FORMATION DAMAGE
}

\author{
Ferenc Remeczki \\ PhD student, Research Institute of Applied Earth Sciences, University of Miskolc \\ 3515 Miskolc, Miskolc-Egyetemváros, e-mail: afkremec@uni-miskolc.hu \\ Gábor Horváth \\ Laboratory expert, Research Institute of Applied Earth Sciences, University of Miskolc \\ 3515 Miskolc, Miskolc-Egyetemváros, e-mail: afkgabor@uni-miskolc.hu
}

\begin{abstract}
In the current study, an investigation possibility is introduced regarding the appearance of the so-called formation damage phenomenon in case of overbalanced drilling of compacted sandstones with waterbased mud and the fracturing of the layers with water-based fracturing fluid. The results presented in the study are part of a series of experiments.
\end{abstract}

Keywords: formation damage, tight sandstone, saturation, experiment

\section{Introduction}

Laboratory methods for measuring petrophysical parameters of compacted sandstones and marls are constantly expanding. It is important to emphasize that for rocks with such unfavorable properties, most laboratory measurements are not made under reservoir conditions mainly in terms of temperature and pressure. A more significant difference, however, is that porosity and permeability measurements are basically carried out with gas, although Mercury injection and pressure pulse decay (PPD) measurements are exceptions in this case. Except for liquid PPD, measurements are made on extracted and dried samples (purified of all liquid content). This information is important, because the measurement results obtained for permeability can be significantly distinct compared to reservoir conditions.

It is well known among the professionals that the pore space of hydrocarbon reservoir rocks has water saturation with different amounts. The value of water saturation is usually interpreted as a distribution function for the entire reservoir, and its value consists of several patterns regarding connate and mobile water.

\section{Theoretical considerations}

In reservoir characterization considering such saturations values is of great importance, especially for reservoirs with significantly low permeability. When talking about the permeability of a reservoir, certain concepts need to be defined. The definition of permeability - for gases - follows from the wellknown relationship established by Darcy's experiments:

$$
q_{a}=-\frac{k_{a} * A}{\mu * L * P_{a}} *\left[\frac{P_{a}^{2}-P_{1}^{2}}{2}\right]
$$


where

- $\mathrm{q}_{\mathrm{a}}$ is the flow rate

$\left(\mathrm{cm}^{3} / \mathrm{s}\right)$

- $\quad \mathrm{k}_{\mathrm{a}}$ is the absolute permeability

(Darcy)

- $\mathrm{A}$ is the cross-sectional area

$\left(\mathrm{cm}^{2}\right)$

- $\mathrm{L}$ is the length

- $\mu$ is the viscosity

(cP)

- $\mathrm{P}_{1}$ is the inlet pressure

(atm)

- $\mathrm{P}_{\mathrm{a}}$ is the outlet (atmospheric) pressure

(atm)

If several immiscible fluids (hydrocarbon-water) or several phases (liquid-gas) are present in the pore space at the same time, these fluids will not flow equally. The percentage of saturation (S) is used to characterize their quantitative share. The sum of the saturations of the different fluids is always $100 \%$. In the simultaneous presence of different fluids, the concept of permeability for a given fluid makes it possible to characterize their flow possibilities which can be defined as effective permeability. In practice, however, relative permeability has become widespread. The relative permeability is possible to be decomposed into effective and absolute permeability:

$$
k_{r}=\frac{k_{e}}{k_{a}}
$$

where

- $\mathrm{k}_{\mathrm{r}}$ is relative permeability

- $\mathrm{k}_{\mathrm{e}}$ is effective permeability

$(-)$

- $\mathrm{k}_{\mathrm{a}}$ is absolute permeability

(Darcy)

The relative permeability for a given fluid is usually plotted as a function of saturation. The following example shows the relative permeabilities compiled from a series of measurements performed on unconventional rock samples (Figure 1).

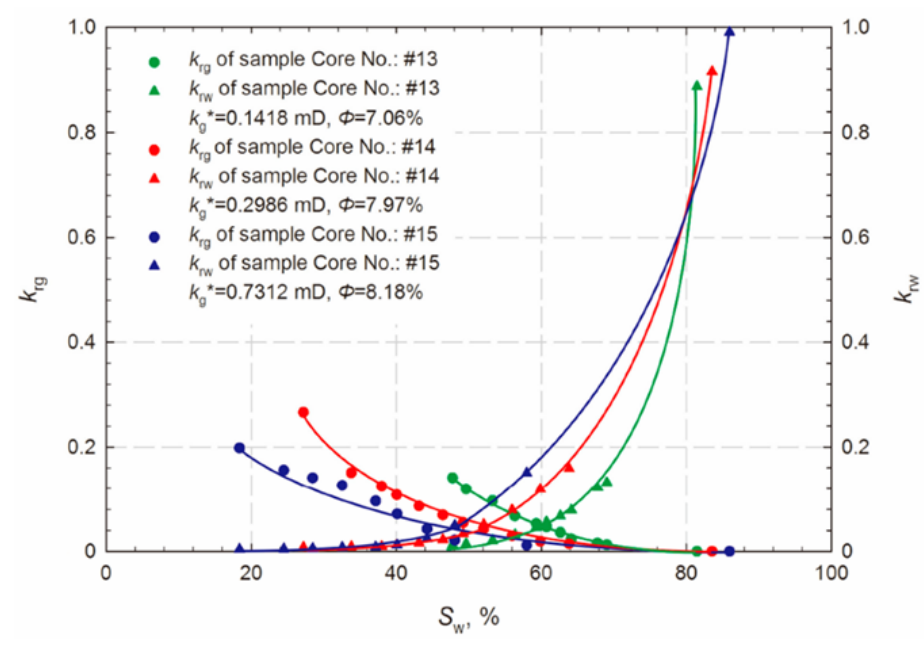

Figure 1. Relative permeability curves from unconventional rock samples measurements [1]

The measurement results of the figure confirm the significant decrease in gas permeability in gaswater systems compared to the gas permeability measured on the dried core. It can also be observed that with increasing value of water saturation the gas is practically no longer flowable. 
In the course of our research, we investigated the possibilities of determining the water saturation of unconventional reservoirs. Based on the available samples and laboratory possibilities, we determined the connate water saturation of certain samples starting from the Mercury injection measurement following Purcell's calculation method [2]. These results predict the presence of significantly high connate water in the reservoirs, respectively. Unfortunately, the production data and experience of domestic unconventional reservoirs do not deny the statement that in case of extremely high water saturation, even if gas production represents, its values are slight.

\section{Experimental application and results}

The aim of the experiments was to investigate how the permeability with respect to the gas changes with increasing water saturation and the pressure differences at which the gas flow can be created. With this series of experiments, we targeted to investigate whether the overbalanced drilling of compacted sandstones with water-based mud and the fracturing of layers with water-based fracturing fluid leads to the so-called formation damage phenomenon or not. In other words, whether a local increase in water saturation impairs gas permeability or not and to what extent.

There are some limitations to laboratory experiments and devices. The selected specimens can be measured in terms of permeability with our conventional instruments, which is important, because samples with lower permeability compared to the selected ones can only be measured with the Nano-K permeameter, which is not suitable to perform gas-water co-flow.

The initial samples of the experiment were extracted under storage conditions (air-dried), their mass was previously measured in a completely dried state (Phase 0 ). In two of the four primary samples selected, a crack is observed on the surface. In the first step of the experiment, the initial water saturation was established by keeping it in steam until constant weight. The experimentation gave an excellent opportunity to test how much saturation can be achieved under laboratory conditions. Subsequently, knowing the volume of the pore space, the samples were flooded with water in several steps, and then the change in gas permeability was measured from the opposite direction. The steps of the experiment are illustrated on Figure 2.
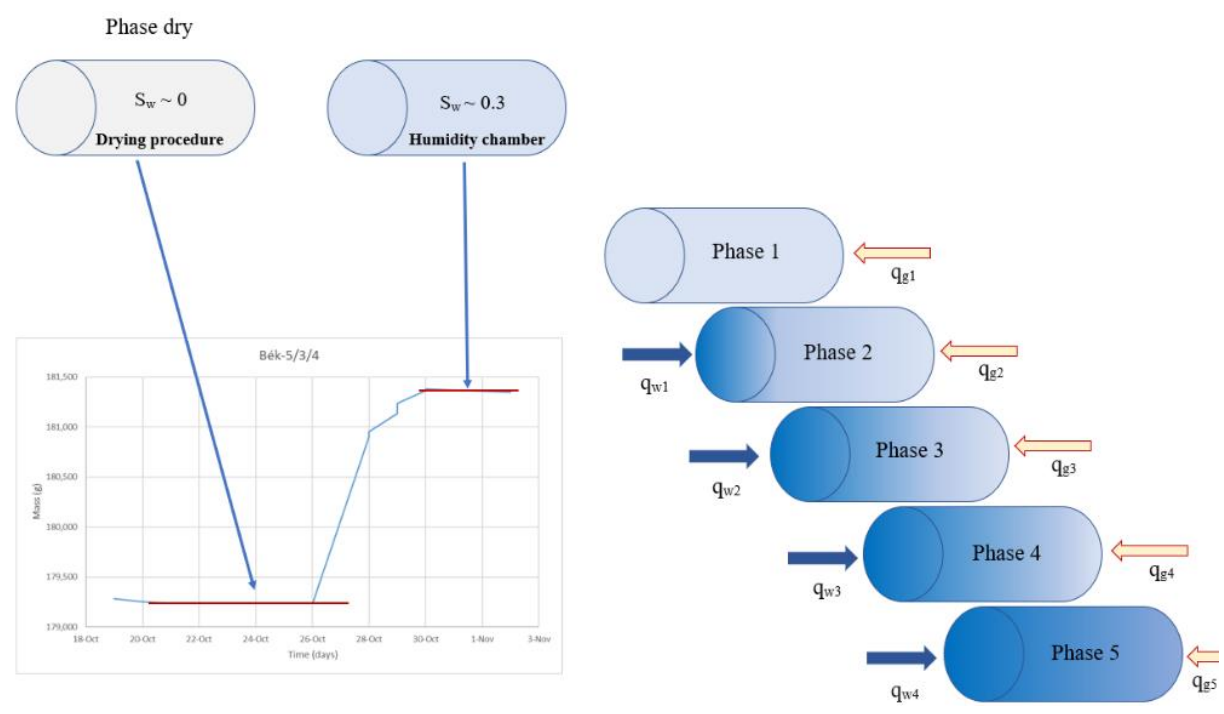

Figure 2. Illustration of experimental phases in case of Bék-5/3/4 sample 
The countercurrent flow maintained with gas also produced water in each case. The saturation conditions were followed in the sample bodies with the highest accuracy possible using available monitoring devices. The water saturation values formed at the end of the phases are shown in Figure 3.

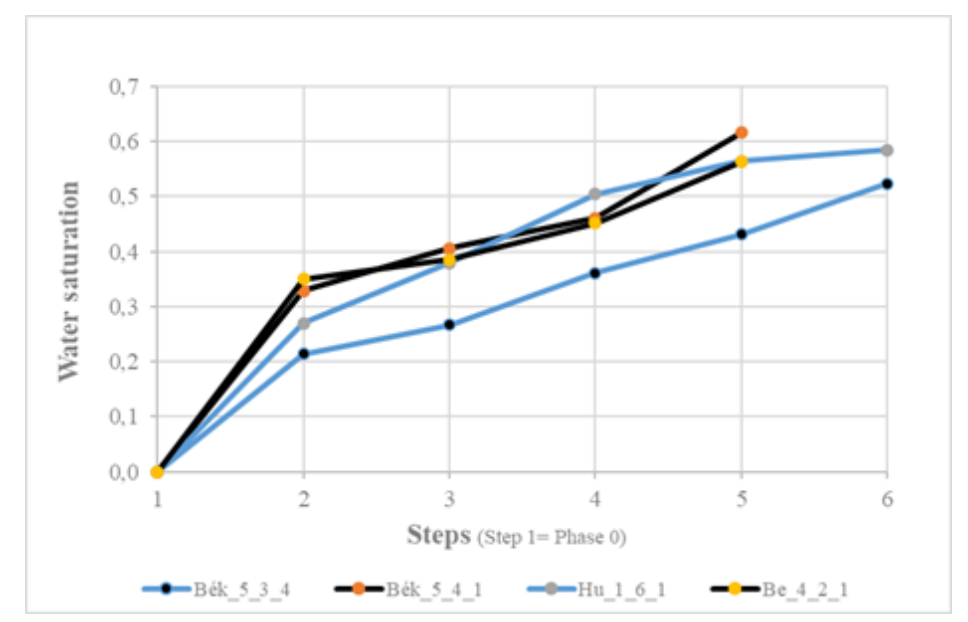

Figure 3. Changing of water saturations during the experiment

The volume of the flowing gas and the permeability to the gas as a function of the required pressure difference were determined for each phase. The results are represented in Table 1. The interpretation has been carried out only from Phase 2, since the water injection was started in that specific step. Due to space limitations, only the results of Bék-5/3/4 are presented in detailed figures. As it can be seen on Figure 4, with increasing saturation, higher pressure differences have to be applied to reach the same gas flow rate.

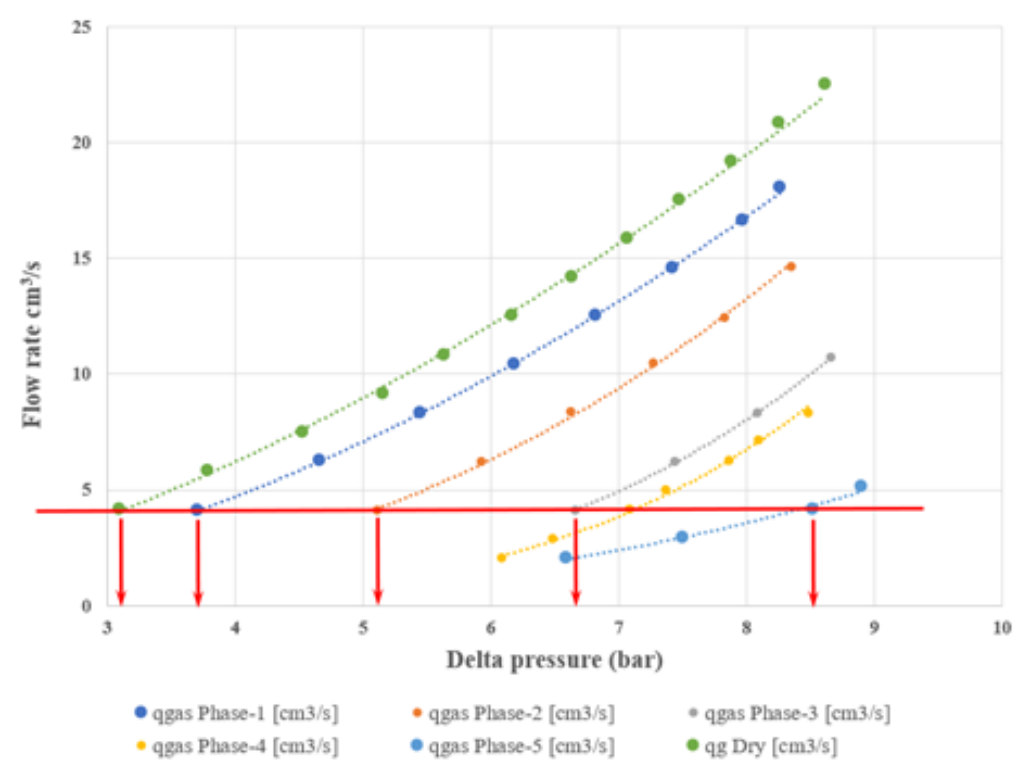

Figure 4. Pressure demand for different flow rates during the measurement of Bék-5/3/4 
Figure 5 demonstrates an interesting trend in permeability change. In terms of all phases, permeability significantly decreases which basically proves the phenomenon of water-based formation damage. However, after the dry phase (Phase 0) an increasing trend can be seen during each phase, which attributable to a so-called 'gas drive effect'. The nitrogen gas that was used during the experiment is barely dissolvable in water, thus in higher saturation values, it is started to push the water out of rock matrix. Although this phenomenon is recognizable in almost every phase, the extent of it decreases when the water saturation reaches extremely high values. After a certain point the formation damage overtakes every other effect and causes the samples to be unmeasurable.

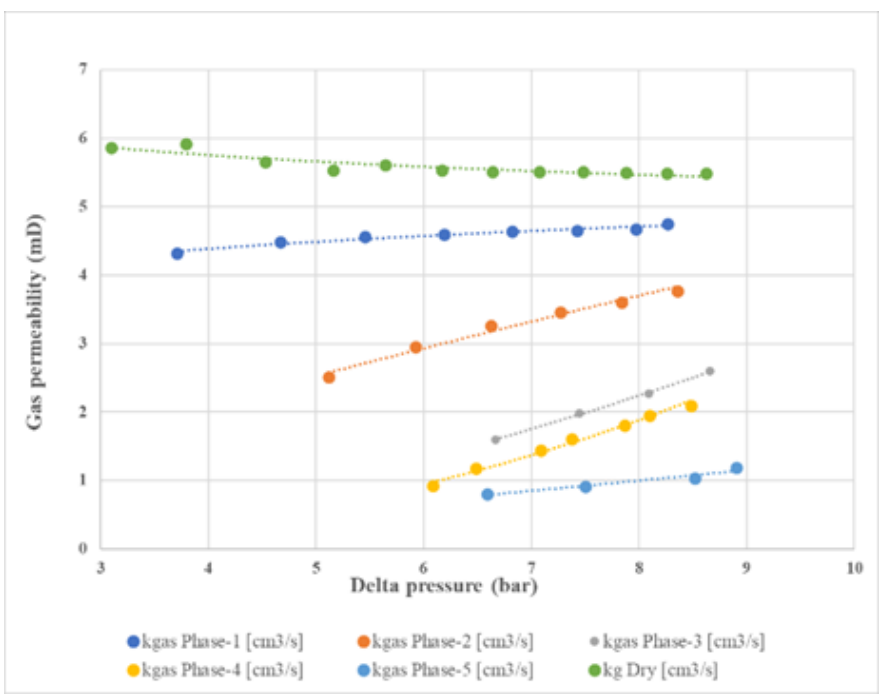

Figure 5. Gas permeability values change in Bék-5/3/4 sample

In each phase (at a given pressure difference), the relative permeability can be calculated from the measured gas permeability, which values plot each point of the relative permeability curve.

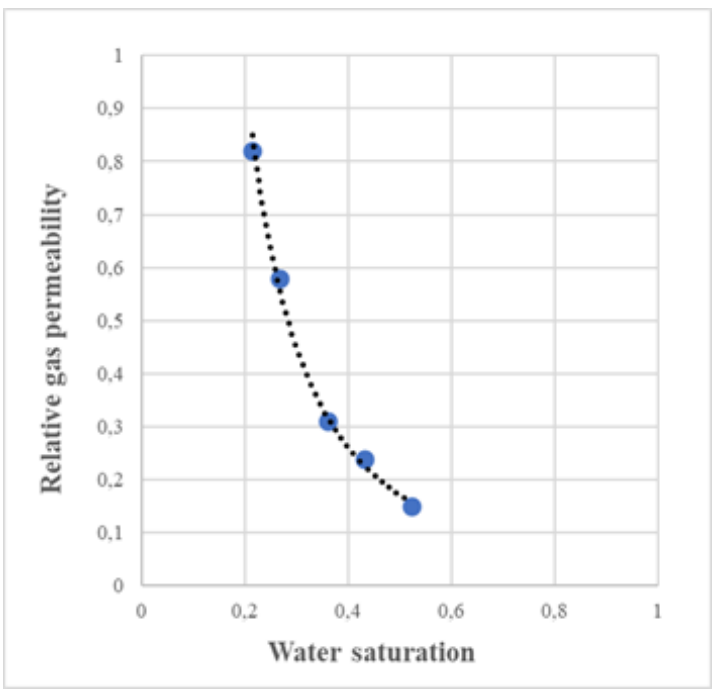

Figure 6. Relative permeability values in the function of water saturation in case of $\Delta p=7$ bar 
Figure 6 is a good illustration of the extent to which the relative gas permeability decreases with increasing water saturation. It is important to emphasize that the value of water saturation is related to the pore volume of the whole sample body, and in the experiment, the water saturation moving from the injection surface to the inside of the sample means a continuously increasing frontal saturation change with respect to the volume (Figure 7).

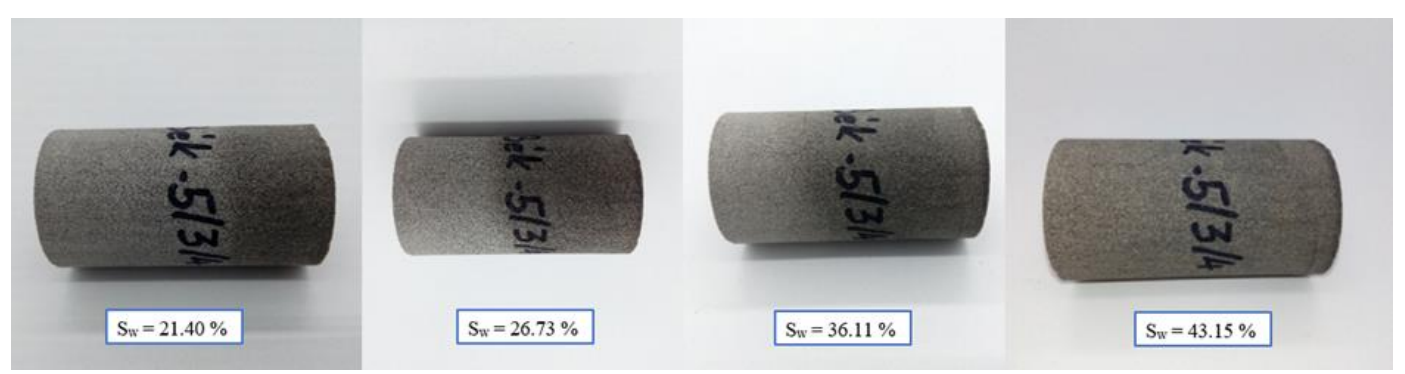

Figure 7. Injected water front changing Bék-5/3/4 sample

There are some ideas for trying to estimate the change in saturation within a volume, but this requires further measurements and knowledge. Based on theoretical knowledge and photographs, it can also be assumed that the values of water saturation near the injection surface are higher than the average for the total volume.

In Phase 0 of the experimental series, water saturation was $0 \%$, after the first phase, it was increased between $21-27 \%$. These saturation states can only be established under laboratory conditions. It is also important to note that during the final phase of the experiment, no water saturation conditions developed that are likely to be in the reservoir. Consequently, the measurement results are more favorable than the values appear to be in-situ. The theoretical connate water saturation determined by the calculation is very high - $80.79 \%$ - in the presented sample (Figure 8).

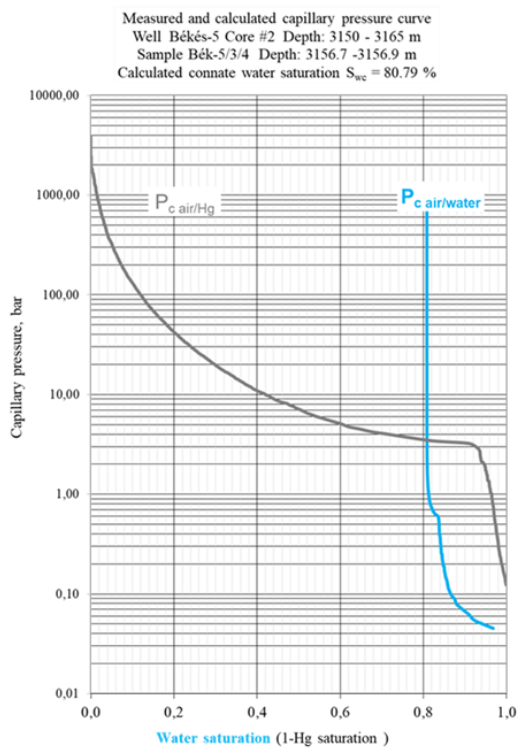

Figure 8. Calculated connate water saturation value along with Mercury/gas and water gas capillary pressure curves 
Taking into account the calculated connate water saturation means that under reservoir conditions, the pore space is filled with approx. 80 percent of non-mobile water, the gas flow is more limited compared to the experiment. Please note that our present laboratory devices are not suitable for reproducing the connate water and gas saturation characteristic of rocks. Nevertheless, it is believed that our results provide a sufficient basis for convincing insights regarding the reduction in gas permeability caused by zones of different water saturation in dense rocks.

\section{Summary}

In our opinion, the series of experiments illustrates the phenomenon of water-induced formation damage in the case of dense sandstone reservoirs. Our results show how flooding a few centimeters from the injection surface significantly impairs the permeability and at the same time increases the pressure difference required to maintain the same flow rate. The performed experiments confirm that the formation damage caused by water injection, significantly increases the degree of required pressure depression from the point of view of production technology. These processes should be considered when exploring and fracturing this type of reservoirs.

\section{Acknowledgement}

The research was carried out in the framework of the GINOP-2.3.2-15-2016- 00010 "Development of enhanced engineering methods with the aim at utilization of subterranean energy resources" project of the Research Institute of Applied Earth Sciences of the University of Miskolc in the framework of the Széchenyi 2020 Plan, funded by the European Union, co-financed by the European Structural and Investment Funds.

\section{References}

[1] Liu, G., Fan, Z., Lu, Y., Li S., Feng B., Xia, Y. and Zhao, Q.: Experimental determination of gas relative permeability considering slippage effect in a tight formation, Energies 2018, 11 (2), 467., 23 February 2018 https://doi.org/10.3390/en11020467

[2] Purcell, W. R.: Capillary pressures - Their measurement using Mercury and the calculation of permeability therefrom, Petroleum Transactions, AIME, Texas, February 1949, Volume 1. no. 2. pp. 39-48. https://doi.org/10.2118/949039-G 


\section{Appendix}

Table 1. Measurement results and parameters of all investigated samples

\begin{tabular}{|c|c|c|c|c|c|}
\hline & & Bék-5/3/4 & Bék-5/4/1 & Нu-1/6/1 & $\mathrm{Be}-4 / 2 / 1$ \\
\hline \multirow{3}{*}{ Phase-2 } & Injected water $\left(\mathrm{cm}^{3}\right)$ & 2.37 & 1.95 & 1.39 & 1.35 \\
\hline & Produced water $\left(\mathrm{cm}^{3}\right)$ & 0.70 & 0.80 & 0.70 & 0.80 \\
\hline & Volume difference $\left(\mathrm{cm}^{3}\right)$ & 1.67 & 1.15 & 0.69 & 0.55 \\
\hline \multirow{3}{*}{ Phase-3 } & Injected water $\left(\mathrm{cm}^{3}\right)$ & 3.07 & 3.58 & 4.04 & 4.18 \\
\hline & Produced water $\left(\mathrm{cm}^{3}\right)$ & 1.30 & 0.80 & 0.70 & 0.80 \\
\hline & Volume difference $\left(\mathrm{cm}^{3}\right)$ & 1.77 & 2.78 & 3.34 & 3.38 \\
\hline \multirow{3}{*}{ Phase-4 } & Injected water $\left(\mathrm{cm}^{3}\right)$ & 5.33 & 4.32 & 3.76 & 3.72 \\
\hline & Produced water $\left(\mathrm{cm}^{3}\right)$ & 1.40 & 1.30 & 0.70 & 3.40 \\
\hline & Volume difference $\left(\mathrm{cm}^{3}\right)$ & 3.93 & 3.02 & 3.06 & 0.32 \\
\hline \multirow{3}{*}{ Phase-5 } & Injected water $\left(\mathrm{cm}^{3}\right)$ & 5.53 & 6.44 & 6.41 & 9.14 \\
\hline & Produced water $\left(\mathrm{cm}^{3}\right)$ & 4.70 & & 2.50 & \\
\hline & Volume difference $\left(\mathrm{cm}^{3}\right)$ & 0.83 & & 3.91 & \\
\hline
\end{tabular}

